\title{
Climate impacts on human livelihoods: where uncertainty matters in projections of water availability
}

\author{
T. K. Lissner ${ }^{1,2}$, D. E. Reusser ${ }^{1}$, J. Schewe ${ }^{1}$, T. Lakes ${ }^{2}$, and J. P. Kropp ${ }^{1,3}$ \\ ${ }^{1}$ Potsdam Institute for Climate Impact Research, P.O. Box 6012 03, 14412 Potsdam, Germany \\ ${ }^{2}$ Geography Department, Humboldt-University Berlin, Berlin, Germany \\ ${ }^{3}$ Dept. of Earth and Environmental Sciences, Potsdam University, Potsdam, Germany
}

Correspondence to: T. K. Lissner (lissner@pik-potsdam.de)

Received: 17 March 2014 - Published in Earth Syst. Dynam. Discuss.: 31 March 2014

Revised: 24 July 2014 - Accepted: 16 September 2014 - Published: 22 October 2014

\begin{abstract}
Climate change will have adverse impacts on many different sectors of society, with manifold consequences for human livelihoods and well-being. However, a systematic method to quantify human well-being and livelihoods across sectors is so far unavailable, making it difficult to determine the extent of such impacts. Climate impact analyses are often limited to individual sectors (e.g. food or water) and employ sector-specific target measures, while systematic linkages to general livelihood conditions remain unexplored. Further, recent multi-model assessments have shown that uncertainties in projections of climate impacts deriving from climate and impact models, as well as greenhouse gas scenarios, are substantial, posing an additional challenge in linking climate impacts with livelihood conditions. This article first presents a methodology to consistently measure what is referred to here as AHEAD (Adequate Human livelihood conditions for wEll-being And Development). Based on a trans-disciplinary sample of concepts addressing human well-being and livelihoods, the approach measures the adequacy of conditions of 16 elements. We implement the method at global scale, using results from the Inter-Sectoral Impact Model Intercomparison Project (ISI-MIP) to show how changes in water availability affect the fulfilment of AHEAD at national resolution. In addition, AHEAD allows for the uncertainty of climate and impact model projections to be identified and differentiated. We show how the approach can help to put the substantial inter-model spread into the context of country-specific livelihood conditions by differentiating where the uncertainty about water scarcity is relevant with regard to livelihood conditions - and where it is not. The results indicate that livelihood conditions are compromised by water scarcity in 34 countries. However, more often, AHEAD fulfilment is limited through other elements. The analysis shows that the water-specific uncertainty ranges of the model output are outside relevant thresholds for AHEAD for 65 out of 111 countries, and therefore do not contribute to the overall uncertainty about climate change impacts on livelihoods. In 46 of the countries in the analysis, water-specific uncertainty is relevant to AHEAD. The AHEAD method presented here, together with first results, forms an important step towards making scientific results more applicable for policy decisions.
\end{abstract}

\section{Introduction}

Processes of global change are closely linked to human wellbeing and livelihood conditions. Global and regional impacts of climate change are expected to affect important societal sectors and have the potential to significantly reduce human welfare (Hare et al., 2011; Schneider et al., 2007; O'Brien et al., 2004). The linkages of various processes of global change to aspects of human well-being and livelihoods have been recognized in different contexts, including climate impacts (O'Brien et al., 2004), sustainable development (Dietz et al., 2009) and ecosystem services (MEA, 2005). While many approaches to define human well-being and livelihoods exist at various degrees of sophistication (O'Riordan, 2013; Alkire, 2002), an operable framework to assess and measure 
human well-being and livelihoods conditions in the context of climate change research does not exist so far. Yet such a framework can provide an important means to assess the consequences of climate change for human welfare and societal systems, allowing for impacts of climate change to be related to other development aspects and impacts across sectors to be compared.

Uncertainty has proved to be a major impediment in climate-related policy decisions. Considerable uncertainty is associated with global models of climate and other biophysical processes, deriving from a range of factors (Schneider and Kuntz-Duriseti, 2002). Different types of uncertainty can be distinguished, some of which can be approached though further research or model improvement (epistemic uncertainty). Other aspects, such as uncertainty from scenarios, cannot be fully eliminated (aleatory uncertainty) (Dessai and Hulme, 2004). Uncertainty is an integral part of scientific analyses; however, in public perception it is often interpreted as ignorance or a lack of robustness (Sigel et al., 2010). To overcome barriers in the translation of scientific results into the policy process, uncertainty needs to be adequately framed (Smith and Stern, 2011). The InterSectoral Impact Model Intercomparison Project (ISI-MIP) (Warszawski et al., 2014) provides an important step towards explicitly and systematically addressing uncertainty deriving from climate impact models and emission scenarios and providing a consistent overview of the range of modelling results. While model improvements may reduce uncertainties to some extent, projections of future changes will always remain subject to aleatory uncertainties, as, for example, development pathways are not knowable. On the one hand, modeland scenario-related uncertainties can be made visible and quantified, as has been done with recent ISI-MIP results. On the other hand, methods to address the relevance of the uncertainty range for specific contexts can help in approaching the topic (Smith and Stern, 2011).

The central objectives of the present paper are two-fold, namely (I) to provide a method which addresses climate impacts in a wider context of human well-being and livelihood needs and (II) to show how this method can address the relevance of uncertainties within such assessments. While uncertainty itself is not reduced through the approach, its relevance for the system under consideration can be determined by viewing the uncertainty range in relation to a specific context. We first outline a novel methodology to measure what is referred to here as AHEAD (Adequate Human livelihood conditions for wEll-being And Development). Based on a transdisciplinary sample of concepts, the approach provides an integrated quantification of livelihood conditions, which allows for climate impacts to be assessed in a comparable way. After an initial implementation of the approach on a global scale, we show how climate- and population change may affect overall fulfilment of AHEAD. For a first implementation of the approach, we focus on the example of water scarcity which has been identified as a major future challenge (Grey et al., 2013).

Recently, Schewe et al. (2014) analysed the range of ISIMIP models to determine developments of water scarcity over the course of the next century. Results show significant uncertainty associated with the output of global water models, which is often even larger than the uncertainty deriving from climate models. We show how the AHEAD approach can provide a framework to view these uncertainties in a context.

Section 2 outlines the background of the AHEAD framework and presents its mathematical representation. We implement the approach in a first calculation, using freely available data at national resolution and with global coverage. To underline the relevance of such an approach for climate impact research, we use results from the ISI-MIP project to outline the effects of changes in water availability on AHEAD. We assess in detail how uncertainties associated with projections of potential future developments can be addressed within the framework. We analyse the results in Sect. 3 and critically discuss the method and results in Sect. 4. A brief conclusion completes our paper.

\section{Methods and materials}

\subsection{Identifying elements of AHEAD}

The aim of the AHEAD approach is to quantify the adequacy of human livelihood conditions for well-being and development, measured through a set of elements. These elements include a range of tangible and intangible aspects, which represent an extended set of basic human needs (Littig and Griessler, 2005). Conceptually, elements of AHEAD are generally valid and globally applicable, allowing for a systematic and comparable assessment of livelihood conditions across space and time.

To derive a consistent set of elements to outline such conditions, AHEAD is based on a transdisciplinary set of approaches, identified through a qualitative literature review (for a detailed outline of the conceptual basis of the AHEAD methodology, see Lissner et al., 2014). On the basis of 11 theories, namely Maslow's theory of human motivation (Maslow, 1943), the basic human needs approach (McHale and McHale, 1979; Doyal and Gough, 1984; Weigel, 1986), human-scale development (Max-Neef, 1992; Cruz et al., 2009), the capability approach (Sen, 1985; Anand et al., 2008; Gasper, 2007; Nussbaum, 2000), human security (Gasper, 2005; UNDP, 1994; King and Murray, 2001), sustainable livelihoods (Scoones, 1998; Chambers and Conway, 1991), quality of life (QoL) (Cummins, 1996; Costanza et al., 2007), subjective well-being (SWB) (Diener et al., 1999, cited in Alkire, 2002), the Millennium Ecosystem Assessment (MEA, 2005), dimensions of poverty (Narayan et al., 2000) and the measurement of economic performance and social progress (Stiglitz et al., 2009), we identify a set of 


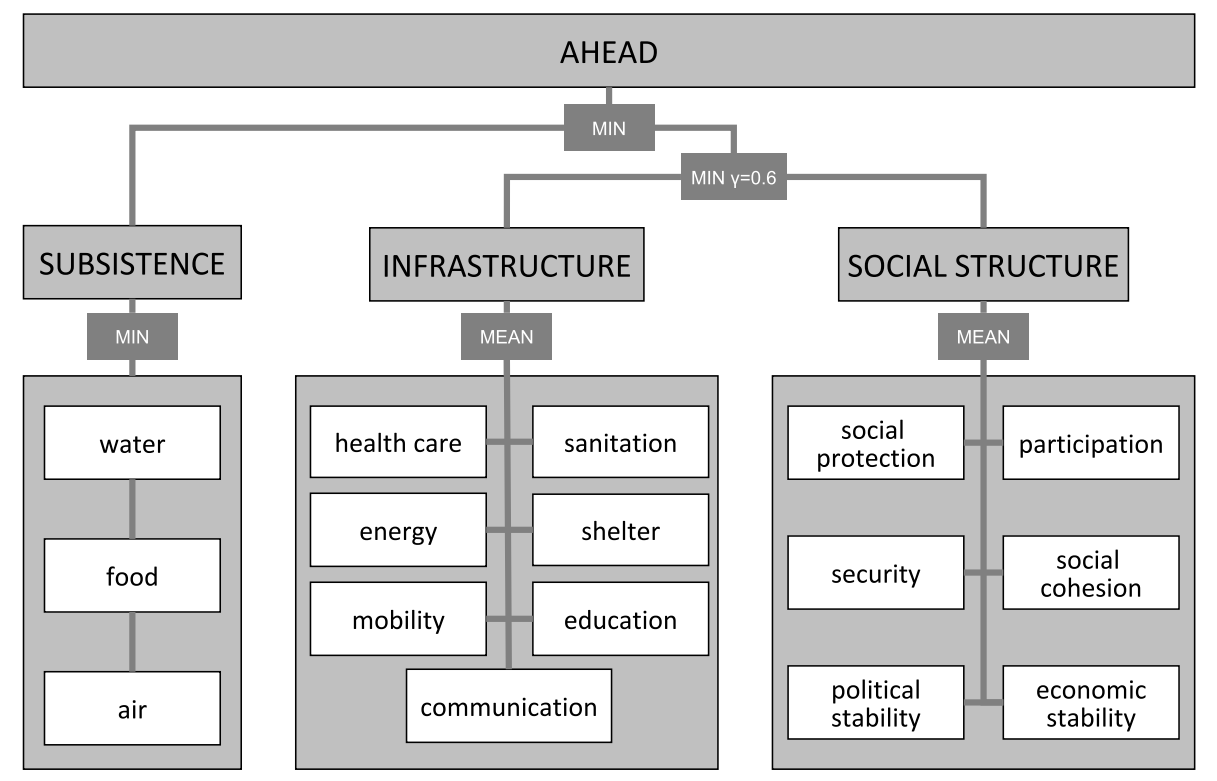

Figure 1. Overview of the fuzzy aggregation tree to calculate AHEAD. Detailed explanations of each variable, as well as the aggregation procedures, are given in Sects 2.2 and 2.3.

16 elements which are relevant to measure AHEAD for climate impact research (see Fig. 1). Detailed descriptions of AHEAD elements are available in the Appendix, Table A1 (Lissner et al., 2014a, published on figshare).

In order to translate these identified elements into a quantified representation, we refer to the conceptual distinction between needs and satisfiers introduced by Max-Neef (1992) (see also Narayan et al., 2000; Sen, 1993). The elements of AHEAD (needs in Max-Neefs definition) constitute essential requirements to attain well-being and adequate livelihoods and are generally valid and globally applicable. However, the satisfiers, which can be used to access these elements and meet needs, may vary across space and time. Different satisfiers may be chosen according cultural preferences or development status, for example, as different kinds of resources can contribute to satisfying the same needs. Further, following the underlying literature, no hierarchy can be assumed to exist between elements, with the exception of those elements directly relevant to physical survival (Max-Neef, 1992; Sen, 1993). For the purpose of measuring the fulfilment of AHEAD, we want to assess whether the availability of each element is adequate to meet human livelihood needs. Adequacy in this context refers to a situation where elements are sufficiently available in quantity and quality to meet basic needs and permit a life in dignity (Wicks, 2012) as recognized, for example, in the Universal Declaration of Human Rights (UN, 1948). Adequate conditions therefore do not refer to a situation of luxury but the sufficient availability of relevant resources. Similarly, inadequate conditions do not necessarily imply complete deprivation but refer to a situation where livelihood needs are no longer met and development is compromised.

To facilitate the measurement of AHEAD, we group the 16 elements into three categories (see Fig. 1). Elements directly relevant to physical human survival are grouped into the domain of subsistence, namely water, food and air. The remaining elements can be grouped according to their tangibility: aspects such as shelter and adequate sanitation provide essential infrastructure. Further elements in this group include education, health care, energy access, communication and mobility. Intangible aspects are relevant in their contribution to the societal structure and include social protection, security, participation, social cohesion, and economic and political stability. In order to provide an estimate of comparable AHEAD at national resolution and global scale, we rely on data sets available at this level of detail and with as few missing values as possible.

The following paragraphs outline the method and discuss available data for a first implementation. We study in detail the relevance of changes in water availability for AHEAD over the course of the century; the remaining elements are kept constant over time.

\subsection{Integrating elements of AHEAD}

Representing the concept of adequacy in mathematical terms can be difficult. The definition of exact thresholds of the sufficient availability of an element can be challenging, due to vagueness and uncertainties associated with such linguistic concepts. Fuzzy reasoning provides a means to express the degree of membership to linguistic concepts, thus translating qualitative elements into quantifiable units (for details see 
e.g. Kropp et al., 2006; Lissner et al., 2012; Zadeh, 1965) and allowing for the consideration of inherent vagueness. By calculating the degree of membership of each variable to a common linguistic category, namely the adequacy of conditions, the diverse range of elements become comparable with regard to their contribution to fulfilled AHEAD conditions.

The first step of the analysis is the fuzzification of the base variables with respect to a defined linguistic category. A function to calculate the degree of membership to the linguistic category is defined for each variable. In the case of our analysis, the degree of membership $\mu$ of each variable to the linguistic category "conditions are adequate" is determined. Fuzzified data sets take continuous values from 0 (adequacy is very low) and 1 (adequacy is very high). For the purpose of determining the fulfilment of AHEAD, fuzzy values near 0 reflect a basic level of resource availability below which development would be compromised. Fuzzy values near 1 indicate a level of sufficiency where basic needs are fully met and conditions are adequate.

Thresholds for membership $\left(\iota_{1}, \iota_{2}\right)$ are defined to calculate continuous degrees of membership $\mu_{z i}$ of variable $\iota$ through Eq. (1) (linear increase), Eq. (2) (linear decrease), Eq. (3) (exponential increase) and Eq. (4) (exponential decrease). For Eqs. (3) and (4), the value of $\epsilon$ determines the curvature of the function. For Eqs. (1) through (4), $\iota_{1}<\iota_{2}$ must be true. As the values for $\iota_{1}$ and $\iota_{2}$ critically determine the membership values for each element and thus the overall result, thresholds have to be context-specific and reflect the properties of the available data. Threshold values and membership functions for the analysis and are discussed in detail in the following Sect. 2.3 and are summarized in Table 1.

$$
\begin{aligned}
& \mu_{z i}(\iota)= \begin{cases}0, & \iota \leq \iota_{1} \\
\frac{\iota-\iota_{1}}{\iota_{2}-\iota_{1}}, & \iota_{1}<\iota<\iota_{2} \\
1, & \iota_{2} \leq \iota\end{cases} \\
& \mu_{z i}(\iota)= \begin{cases}1, & \iota \leq \iota_{1} \\
\frac{\iota_{2}-\iota}{\iota_{2}-\iota_{1}}, & \iota_{1}<\iota<\iota_{2} \\
0, & \iota_{2} \leq \iota\end{cases} \\
& \mu_{z i}(\iota)= \begin{cases}0, & \iota \leq \iota_{1} \\
\frac{1}{1-\exp (-\epsilon)} \times\left(1-\exp \left[-\epsilon \frac{\iota-\iota_{1}}{\iota_{2}-\iota_{1}}\right]\right), & \iota_{1}<\iota<\iota_{2} \\
1, & \iota_{2} \leq \iota\end{cases} \\
& \mu_{z i}(\iota)= \begin{cases}1, & \iota \leq \iota_{1} \\
\frac{1}{1-\exp (\epsilon)} \times\left(1-\exp \left[-\epsilon \frac{\iota_{2}-\iota}{\iota_{2}-\iota_{1}}\right]\right), & \iota_{1}<\iota<\iota_{2} \\
0, & \iota_{2} \leq \iota\end{cases}
\end{aligned}
$$

Subsequent to their fuzzification, variables are aggregated using context-specific aggregation rules in a defined order (Fig. 1). The choice of aggregation rules should reflect the context of the analysis and be motivated by the properties of the indicators. Fuzzy decision rules thus allow for incorporation of the content-related properties of, and relationships between, variables. Operators for the aggregation are defined analogously to crisp set theory and additional fuzzy operators are available (Mayer et al., 1993). Unlike the strict application of boolean MIN or MAX operators, which result in a strict intersection or union of sets, fuzzy operators allow for compensation through a $\gamma$ value, which can take values between 0 and 1 (Eq. 5 for fuzzy MIN; analogue quantification for fuzzy MAX) (Kropp et al., 2001). The introduction of $\gamma$ results in the consideration of the arithmetic mean of all input values to some extent, thus diluting the strict application of the operator to the extent of $\gamma$, with values near 1 resulting in a rather strict application of the operator and values near 0 introducing significant compensation. At $\gamma=0$ the arithmetic mean of the input values is calculated.

$$
\begin{aligned}
\mu\left(z_{1} \wedge z_{2} \wedge \ldots \wedge z_{n}\right) & =\gamma \times \min \left(\mu_{z 1}, \mu_{z 2}, \ldots, \mu_{z n}\right) \\
& +(1-\gamma) \times \frac{1}{N} \sum_{i=1}^{N} \mu_{z i}
\end{aligned}
$$

To assess the fulfilment of AHEAD, the characteristics of the contributing elements as well as their relationships determine the rules and order of aggregation, as outlined in Fig. 1. Initially, the three dimensions of subsistence, infrastructure and societal structure are aggregated individually. An essential property of the elements of the subsistence dimension is that they are non-substitutable: if one of the elements of water, food or clean air is not available, it poses a direct threat to human health and well-being. Indicators within this dimension are therefore aggregated using a strict MIN operator with $\gamma=1$ (left column of Fig. 1). Elements relevant for the societal structure dimension, however, may to some extent be substitutable. Low availability of one resource may to some extent be compensated for by the high availability of another, which is reflected in using the arithmetic mean $(\gamma=0)$ (right column of Fig. 1). While those elements included in the infrastructure dimension are not substitutable in a physical sense, high values in one of these domains imply high levels of technological advancement, which motivates the use of the arithmetic mean here (middle column of Fig. 1). The final aggregation of the three dimensions to the full index of AHEAD reflects the fact that all three components are required to attain adequate conditions. We aggregate the dimensions infrastructure and societal structure using a fuzzy MIN operator with $\gamma=0.6$. This use of $\gamma$ accounts for the fact that levels of adequacy in both dimensions are required for fulfilled livelihoods, but fully adequate conditions in one area may compensate for other deficiencies to the extent of $\gamma$. While the order of magnitude and likely ranges of $\gamma$ can be motivated by the context, the exact value is to some extent arbitrary within the global implementation of the approach. The subsequent aggregation of all dimensions to a measure of AHEAD is performed using a strict MIN operator $(\gamma=1)$, again reflecting the nonsubstitutability of the subsistence domain. 


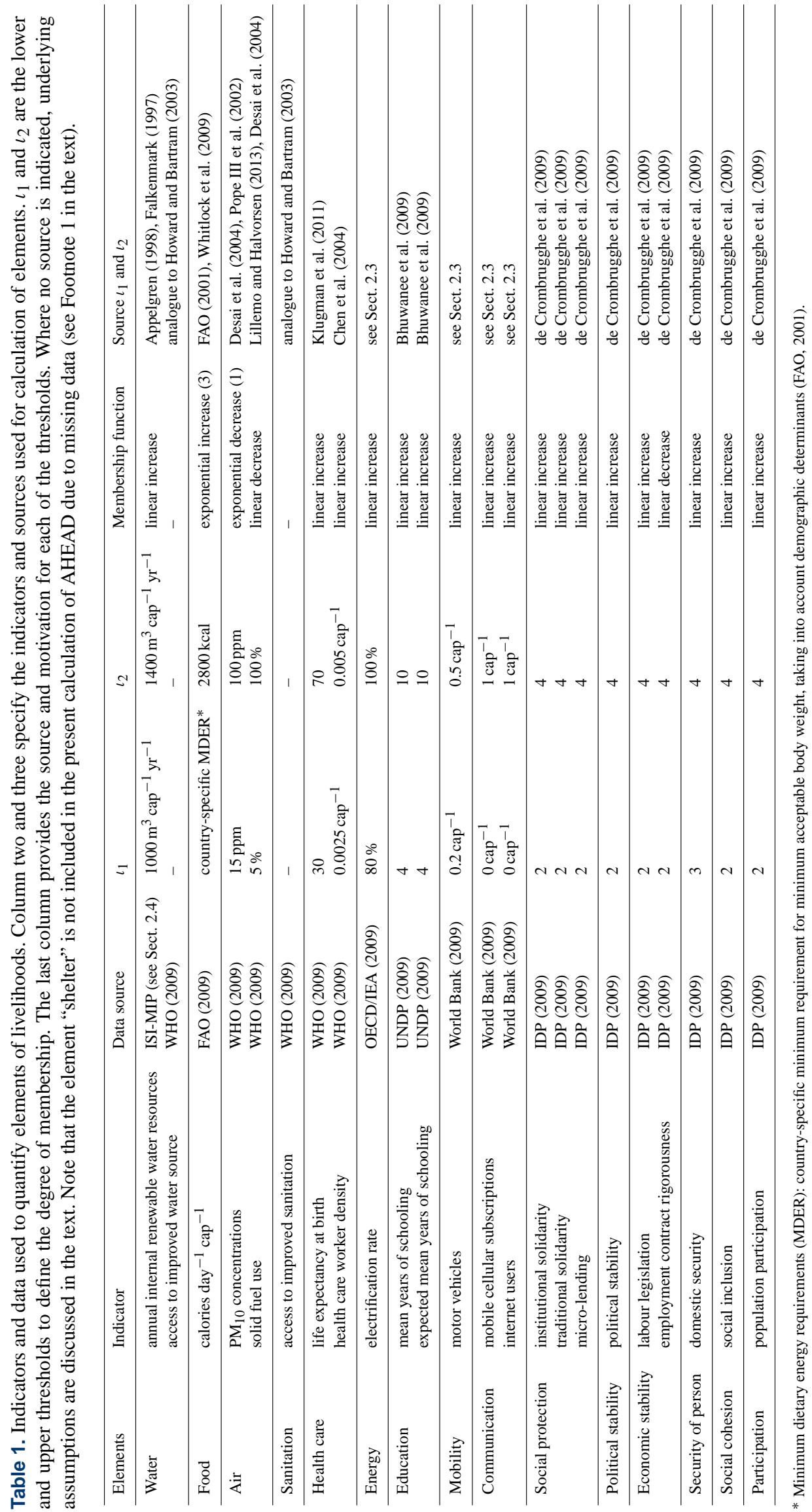




\subsection{Data and fuzzy membership functions to calculate the fulfilment of AHEAD}

We implement the AHEAD index at global scale, relying on freely available data at national resolution (Table 1). As we rely on data sets that are available with global coverage, the consideration of possible satisfiers is limited in some cases, as only selected indicators are raised at this scale. Applied fuzzification methods for each variable are motivated by results from the literature as presented in Table 1. A more detailed summary of the translation of elements into a quantified representation is available in the Appendix (Table A1) (Lissner et al., 2014a). Most elements can be represented with single data sets (Table 1). For the representation of some elements, composite indicators have to be calculated, which are derived as follows:

- Water: sufficient water availability is essential both directly, in terms of drinking water, and indirectly, as an essential prerequisite for other elements, such as food and energy production. Drinking water availability is often not restricted by actual resource availability, but rather low quality or unimproved access are limiting factors (Rijsberman, 2006). Looking beyond physical water resources alone, "water" is therefore represented using the two indicators "access to improved water source" and "available water resources", aggregated via a MIN operator. Adequate water resource availability refers to the cumulative water needs of all sectors.

- Air quality: both indoor and outdoor air quality determine health effects. The main determinant for indoor air quality is the use of solid fuels for heating and cooking, whereas negative health effects of outdoor air derive mainly from concentration of particulate matter (PM) (Klugman, 2011). The two indicators "solid fuel use" and " $\mathrm{PM}_{10}$ concentration" are aggregated using a MIN operator.

- Health care: the human development index (HDI) includes the indicator "life expectancy at birth" to represent the capability of leading a long and healthy life (Klugman et al., 2011). We combine the indicator with the average "number of doctors per capita" using the arithmetic mean.

- Social protection: refers to a source of support available should one not be able to support oneself. In our analysis we identified three indicators, which can provide this support: "institutional solidarity", "traditional (community) solidarity" as well as "access to microcredits" (de Crombrugghe et al., 2009). As either one of these can fulfil the need for support, we use a MAX operator for the aggregation.

- Economic stability: refers to conditions that enable the population to plan ahead and feel secure regarding the prospects for the future. We use the "existence of labour legislation" and the degree of "rigidity of employment contract" to represent "economic stability" (de Crombrugghe et al., 2009). Indicators are aggregated with the arithmetic mean.

- Education: we use the HDI 2010 methodology (Klugman, 2011), which represents access to education with the two indicators "mean years of schooling" and "expected mean years of schooling", aggregated with the arithmetic mean.

- Communication: we combine the indicators "number of mobile phones" and "number of internet users" as representatives of access to communication infrastructure, which have been recognized as essential tools of development (UN ICT Task Force, 2005), using a MAX operator.

Thresholds $\iota_{1}$ and $\iota_{2}$, as well as the shape of the membership function (Eqs. 1-4) to fuzzify each input data set, which are discussed in the following paragraphs, are motivated by the literature (for an overview of all membership functions, as well as the frequency distribution of the input data, see Fig. A1a and A1b in the Appendix). For the purpose of representing the adequacy of "available water resources" for AHEAD, we use the Falkenmark indicator, which defines a range of per capita water resource needs based on empirical estimates, including the domestic, agricultural and industrial sectors. We note that the application of such globally homogeneous thresholds represents a simplification which we deem appropriate for the purpose of the present global study. Annual renewable water resources per capita $\left(\mathrm{m}^{3} \mathrm{cap}^{-1} \mathrm{yr}^{-1}\right)$ below $500 \mathrm{~m}^{3} \mathrm{cap}^{-1} \mathrm{yr}^{-1}$ indicate absolute water scarcity $\left(\iota_{1}\right)$, while an availability of more than $1400 \mathrm{~m}^{3} \mathrm{cap}^{-1} \mathrm{yr}^{-1}$ indicates no water stress (water security) ( $\left.\iota_{2}\right)$ (Falkenmark, 1997; Falkenmark and Rockström, 2004; Brown and Matlock, 2011). Data sets for the variables "access to improved water source" as an additional aspect of water availability and "access to improved sanitation" are grouped into three and four classes, representing the quality of access. For each country, the available data provides the percentage of households belonging to the respective class. To make use of this classification, we weigh each group according to the quality of access, as outlined in Howard and Bartram (2003). The classification and associated weights are as follows: access to water: (a) piped onto premises, weight 1 , (b) other improved water source, weight 0.6 , and (c) unimproved water source, weight 0.2 ; sanitation: (a) improved sanitation, weight 1 , (b) shared facilities, weight 0.6 , (c) unimproved sanitation, weight 0.2 , and (d) open defecation, weight 0 . The classes are then summed up, resulting in continuous values between 0 and 1, indicating the overall degree of adequacy of access.

It has been shown that a moderate increase in calorie intake has higher nutritional benefits at the lowest levels of 
calorie intake, approximated here by the use of a curved membership function (Eq. 3) with $\epsilon=3$ (Whitlock et al., 2009). Lower and upper thresholds refer to specifications by the FAO, who calculate minimum dietary requirement (MDER) for all countries, reflecting the demographic situation, and propose a global average ideal nutrition level of 2800 calories cap ${ }^{-1}$ day $^{-1}$ (FAO, 2001). The effects of particulate matter on human health are especially strong at concentrations above $100 \mathrm{ppm}$, while levels below $15 \mathrm{ppm}$ are acceptable (Desai et al., 2004); at lower concentrations, health effects decrease (Pope III et al., 2002). The thresholds for the variables life expectancy at birth and actual and expected mean years of schooling are set as used for the calculation of the HDI 2010 (Klugman et al., 2011). Adequate health coverage is likely to be achieved with a minimum health worker density of at least $0.0025 \mathrm{cap}^{-1}$ and should be guaranteed at a density of $0.005 \mathrm{cap}^{-1}$ (Chen et al., 2004).

Membership to the linguistic variable "indoor air quality is adequate" is calculated using the indicator "solid fuel use". As some use of solid fuels can have lifestyle aspects, such as in fireplaces (Lillemo and Halvorsen, 2013), we set the lower threshold to $5 \%$, which represents fully adequate conditions. Membership decreases linearly up to a solid fuel use of $100 \%$. We set the minimum electrification at $80 \%$ and calculate a linear increase of membership up to $100 \%$, reflecting the fact that energy access is fundamental to many livelihood aspects, e.g. communication and most general household needs (Gaye, 2008), and restricted access also restricts many other livelihood needs. Both indicators for communication, the number of internet and mobile phone users, are fuzzified using continuous values between 0 and $1 \mathrm{cap}^{-1}$. For the fuzzification of mobility data we set $\iota_{1}$ to 0.5 motor vehicles per $\mathrm{cap}^{-1}$, as this reflects the lowest values of high HDI countries (World Bank, 2009). Similarly, $\iota_{2}$ at $0.2 \mathrm{cap}^{-1}$ reflects values in very low HDI countries.

Input data available to measure the societal structure are ranked continuously on a scale from 0 or 1 to 4 . This ranking scale stems from the collection and preparation methodology of the data, where values of 0 mean that the respective element is not available at all, values near 1 represent low values and values of 4 indicate high availability or fulfilment of the respective element (de Crombrugghe et al., 2009). The linguistic representation of adequacy is thus already implemented in the initial classification and can directly be used in the fuzzy logic algorithm. Table 1 summarizes the relevant parameters for the fuzzification of elements and specifies the data sets and sources used (also see Appendix, Table A1, for further details on the indicators used).

Data coverage differs slightly for the three dimensions of AHEAD and each dimension has missing values for some countries; the full measure was calculated for all cases with full data coverage across elements (111 countries). Shelter is the only aspect that cannot be represented adequately because of missing data and is therefore not included in the present analysis ${ }^{1}$. For the majority of indicators, no consistent scenarios are available. To address the question of how potential climate change impacts may affect human livelihood conditions, we employ data from ISI-MIP to address how changes in water availability affect AHEAD fulfilment.

\subsection{Scenarios of water availability}

For the analysis of water resource availability, we use global gridded runoff and discharge data, which has been calculated in the framework of ISI-MIP (Warszawski et al., 2014). Simulations were performed with eleven impact models (IM), namely the hydrological models DBH (Tang et al., 2007), H08 (Hanasaki et al., 2008), Mac-PDM.09 (Gosling and Arnell, 2011), MATSIRO (Takata et al., 2003), MPI-HM (Stacke and Hagemann, 2012), PCR-GLOBWB (Wada et al., 2010), VIC (Liang et al., 1994), WaterGAP (Döll et al., 2003), and WBMplus (Wisser et al., 2010); the land-surface model JULES (Best et al., 2011); and the LPJmL (Bondeau et al., 2007) dynamic global vegetation model. The models were driven by bias-corrected (Hempel et al., 2013) climate data from five global climate models (GCM) that participated in the fifth phase of the Coupled Model Intercomparison Project (CMIP5; Taylor et al., 2012), based on four Representative Concentration Pathways (RCPs; Moss et al., 2010). As a first-order indicator of available renewable freshwater resources, we calculate annual mean runoff at each grid cell, and then redistribute it within each river basin according to the spatial distribution of discharge to account for crossboundary flows between countries (Gerten et al., 2011). The result is summed up over every country and divided by the country's population to obtain water resources per capita per year. Country-level population data according to UNWPP estimates for the historical period, and according to the Shared Socioeconomic Pathways SSP2 (O'Neill et al., 2012) projection for the future, are obtained from the SSP database at https://secure.iiasa.ac.at/web-apps/ene/SspDb and linearly interpolated to obtain annual values. For further details about the model simulations, see also Schewe et al. (2014). We calculate average per capita water availability for a baseline of 1981-2010 (2000) and calculate projected changes for the scenario period 2071-2099 (2090). Years in brackets will be used throughout the paper as a reference to the 30-year average. We calculate water availability for each RCP and each IM-GCM combination individually and also calculate the average across models (ensemble mean). Per capita water

\footnotetext{
${ }^{1}$ Data on housing availability and quality is scarce. The available slum indicator used for measuring the Millennium Development Goals, for example, is an aggregate of five indicators: access to improved water, access to improved sanitation, sufficient living area, durability of housing, and security of tenure, of which only access to improved water and sanitation have acceptable coverage (143 countries, compared to 53 to 68 countries for the other indicators). Both of these indicators are resolved individually in the analysis (source: http://www.unhabitat.org/stats/.
} 


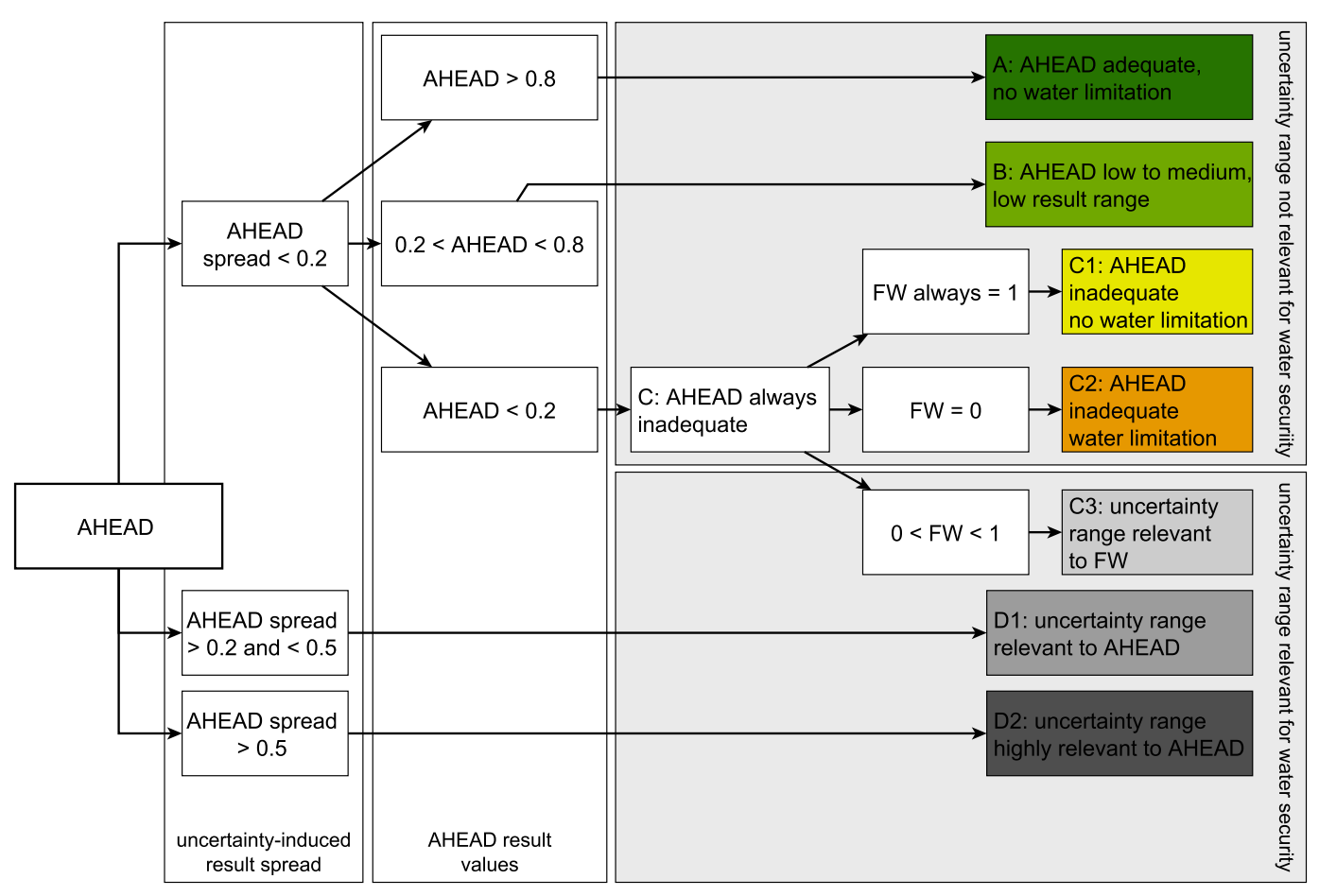

Figure 2. Decision tree to classify AHEAD results according to the result range of water availability data. Note that the term "range" in the figure refers to the range of result values for a single country, deriving from the range of values of water resource of availability from the different IM-GCM-RCP combinations. FW refers to fuzzified values of water availability. Classes A, B and C.1, C.2 comprise results which show a low range of values, indicating that the uncertainty-induced result range lies outside relevant boundaries for adequate AHEAD conditions and water security. In class C.3 and all D classes, uncertainty ranges are relevant with regard to AHEAD conditions and/or water security.

availability is then translated into fuzzy values as discussed in the previous section. We include scenario data for water availability only; other elements of AHEAD are kept constant over time. Changes in conditions are thus a function of changes in water availability over the course of the century.

\section{Assessment of the relevance of uncertainty}

Finally, we analyse AHEAD results with regard to the relevance of the uncertainty associated with the RCPs as well as the IMs and GCMs. As a result of the different levels of warming associated with the RCPs, as well as differences between models, projections of future water availability differ, leading to a spread of results (inter-model spread).

We categorize our results according to the relevance that this inter-model and scenario spread has for the results of our analysis. Following the decision tree outlined in Fig. 2, we differentiate between several combinations which determine whether the modelling- and scenario-induced uncertainty affect AHEAD results. As the inter-model and scenario spread leads to a range of possible values of water resource availability, there is a consequent range of possible fuzzy values of water availability for AHEAD conditions. "AHEAD spread" in the context of this analysis refers to the differences between the minimum and maximum possible values of aggregated AHEAD conditions as a result of the inter-model and scenario spread in projections of water availability in a given time period. In groups A, B and C.1/C.2 indicated in Fig. 2, the spread is not relevant with regard to the defined context-specific membership functions and decision rules, and the country-specific result spread of aggregated AHEAD values is below 0.2 . The result range is low, either because water is not limited (fuzzy water value of 1), regardless of the spread of the modelling output (A, C.1), because there is high agreement in the models and the result range is small (B) or because water is severely limited (fuzzy water value of 0) under all scenarios and models (C.2). For group C.3 and all subgroups of $\mathrm{D}$, the spread affects the results of fuzzy water values and overall AHEAD conditions and cannot be factored out. Here, we further differentiate results according to the magnitude of the spread. Group D.1 has a countryspecific AHEAD result spread between 0.2 and below 0.5, whereas the result spread in class D. 2 is 0.5 or higher. 


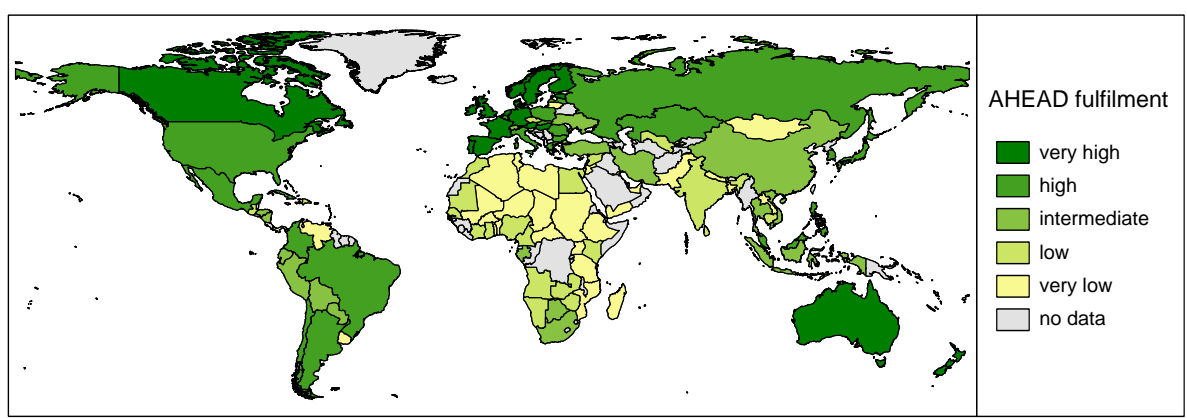

Figure 3. AHEAD fulfilment at global scale for present conditions (water data: ensemble mean across all participating ISI-MIP climate and water models for the baseline 2000). Result values for current and future calculations for all GCMs and RCPs are published on figshare (Lissner et al., 2014a).

\section{Results}

\subsection{Current and future fulfilment of AHEAD}

The following paragraphs present the results of the analysis, based on the ensemble mean of the underlying scenarios of water availability. All country- and indicator-specific values using the ensemble mean and the results of the individual IM-GCM-RCP combinations are available in the Appendix (Lissner et al., 2014a). The initial fuzzification of all input values leads to comparable values between 0 and 1 , describing the adequacy of each AHEAD element. The directed aggregation procedure then allows for quantifying the adequacy of conditions of the three subindices subsistence, infrastructure and societal structure, as well as the overall fulfilment of AHEAD. The fuzzified and aggregated values can be represented according to the degree of membership to the linguistic category of adequacy: very high $(1-0.8)$, high $(<0.8-0.6)$, intermediate $(<0.6-0.4)$, low $(<0.4-0.2)$ and very low $(<0.2-0)$.

Figure 3 shows overall global livelihood conditions for baseline conditions (2000), using per capita water availability from the ensemble mean. Based on these values, global mean AHEAD fulfilment is intermediate (0.48). Only a few changes in overall AHEAD fulfilment occur for the future scenario based on ensemble mean values; therefore only baseline values are presented in Fig. 3. Calculations using the full range of ISI-MIP modelling results for the baseline as well as the scenario period as input for water availability lead to a result spread of intermediate to low AHEAD fulfilment on global average (between 0.34 and 0.53 ). The general spatial distribution of AHEAD is similar across all scenarios and models. A total of 9 (22) countries consistently show very high (very low) AHEAD fulfilment in all model and scenario combinations, while the results from 80 countries vary as a result of different values of water availability.

When comparing the adequacy values for the three subindices in terms of the main limitations on the basis of the ensemble mean, the societal structure is most limited in 47 countries, while subsistence and infrastructure pose strong limitations in 37 and 27 countries, respectively. While this differs slightly across models and scenarios, as water limitations are higher or lower, the general distribution is nonetheless consistent and societal aspects limit AHEAD fulfilment in many regions. With the regard to the highest adequacy of conditions, values in the subsistence domain are highest in 51 countries, while this is true for 33 and 27 countries for the societal structure and infrastructure domains, respectively (see Table A1 for a summary of the degree of fulfilment of all AHEAD elements and subindices; individual country values in the Appendix).

From closer inspection of the single elements of AHEAD, it becomes apparent within the subsistence subindex that it is most often the inadequate air quality which limits the adequacy of conditions (baseline: 61; 2090: 59). On the basis of the ensemble mean, water availability is the strongest limitation (36 for 2090 values) for the baseline in 34 countries, while calorie availability and water access limit the subsistence subindex in 1 and 15 countries, respectively. Nonetheless, water limitations are also present in many regions where other elements present the highest limitations to AHEAD. Of the 111 countries, 67 countries have fuzzy water values below 1; however, in 32 of these, water availability is only slightly below the threshold and adequacy is very high. In 44 countries, no limitations are present (fuzzy water is 1), while fuzzy water availability is below 0.6 in 21 countries. The calculations for 2090 show slight reductions in the adequacy of water availability. In 43 countries, water availability remains above thresholds of water security, and in 27 countries the adequacy of water availability is very high. The number of countries with values of below 0.6 increases to 30 for 2090. Within the infrastructure domain, the elements mobility, energy availability and communication show the highest limitations, with minimum values in 52, 29 and 22 countries, respectively. In the societal structure, the main limitations show in the elements participation (59) and economic stability (22). 


\subsection{The relevance of uncertainties in projections of water availability for AHEAD}

Uncertainties in climate impact analyses derive from various sources. In the present results, uncertainties deriving from the inter-model spread of both GCMs and IMs as well as from greenhouse gas scenarios are visible in the results, as they produce a range of potential future developments of water availability. Further sources of uncertainty, such as an incomplete understanding of underlying processes (see e.g Schneider and Kuntz-Duriseti, 2002, for a detailed overview), exist; however these are not in the focus of the present analysis. The AHEAD methodology allows for the uncertainty-induced result range within a context to be viewed, which allows for determination of whether this specific type of uncertainty is relevant with regard to a specific question, in this case the adequacy of water resources and AHEAD fulfilment. In the remainder of the paper, uncertainty specifically refers to modelling- and scenario-induced uncertainties which produce a visible result range (intermodel spread).

The basic idea of the approach is simple: if the uncertainty causes AHEAD results to cross the thresholds of adequacy, uncertainties are relevant to the fulfilment of AHEAD. If this is not the case, uncertainty is not relevant with regard to the specific context, here the adequacy of conditions. Figure 4 exemplifies in more detail how the fuzzification and aggregation procedures allow for the relevance of uncertainty to be assessed for AHEAD results by showing three subsequent analysis steps in several example countries: plots on the left show the overall per capita water availability $\left(\mathrm{m}^{3} \mathrm{cap}^{-1} \mathrm{yr}^{-1}\right)$. The middle and right plots present fuzzified values for water availability and AHEAD, respectively. In each plot, the individual IMs and the two time slices are plotted individually, showing the result spread across GCMs and RCPs. From comparison of the modelling results regarding water availability per capita (plots a-c), it is clear that Sweden in this example has the highest spread stemming from both IM and GCMs, with modelled ranges of water availability of up to $13240 \mathrm{~m}^{3}$. When translating these values into a fuzzy representation of the adequacy of water availability (plots e-f), however, it becomes apparent that this range is outside of values relevant to water security (fuzzy water availability is 1), as water supply in both countries is always adequate under all scenarios. The modelling- and scenariorelated uncertainty present in the results is thus large, but it is unlikely to affect human water security in the context of AHEAD. The two other examples, Morocco and Ethiopia, have smaller result ranges of per capita water availability across models and scenarios. When translated into a fuzzified representation of water adequacy, however, it becomes clear that these ranges may be highly relevant to water security, as many of the potential future projections lie within a range of beginning or existing water scarcity. The third column (plots $\mathrm{g}-\mathrm{i})$ shows the resulting values of AHEAD for each country.
In two of the examples, the result range of modelled water availability does not affect overall AHEAD conditions, either because the water availability is always above the relevant thresholds (Sweden), or because other factors determine the overall result (Ethiopia). In Morocco, water availability values are all within a critical range for water security, and this remains visible within the overall results of AHEAD.

In this manner, the decision tree shown in Fig. 2 allows for the results for each country to be classified according to the relevance of uncertainty for water security and overall AHEAD fulfilment. We use the value range across all models and scenarios for the classification, but differentiate between the time slices 2000 and 2090. The map in Fig. 5 shows the resulting grouping of countries for baseline conditions, with grey colours representing groups with relevant uncertainty (C.3 and D). There are only a few changes in this classification in the future scenario (see Appendix for all countryspecific values).

Of the 111 countries for which AHEAD could be calculated, the current model spread in 65 countries is outside the thresholds for AHEAD fulfilment. This number increases to 70 countries in 2090, as water scarcity increases and water security is below the minimum requirements in all RCP-IMGCM combinations. The reduction of uncertainty is due to the high model agreement with regard to reduction in water availability to levels where water scarcity has to be expected. Those countries which move towards classes where uncertainty is not relevant to water security move to classes which show very low values of fuzzy water availability. In 54 of the countries outside the uncertainty range, there is agreement between models, scenarios and time periods that water resources are adequate and fuzzy water values are high to very high. In 11 countries (16 in 2090), models agree on severe limitations to water availability (fuzzy water availability is 0 ).

\section{Discussion}

While information on sectoral climate change impacts is increasing, a generally applicable framework to relate climate impacts to livelihood conditions and human well-being is so far unavailable. We present an approach to quantify adequate human livelihood conditions for well-being and development and link these conditions to assessments of climate impacts, exemplified with changes in water availability. Based on a set of 16 elements to represent requirements for human wellbeing and livelihood conditions, the AHEAD approach provides a means to view climate impacts in a wider context, focussing on their relevance for human development.

The approach measures elements within the three dimensions of subsistence, infrastructure and societal structure. Conceptually, the identified elements of AHEAD constitute generally valid requirements for adequate livelihoods. Their fulfilment can be measured through indicators, 

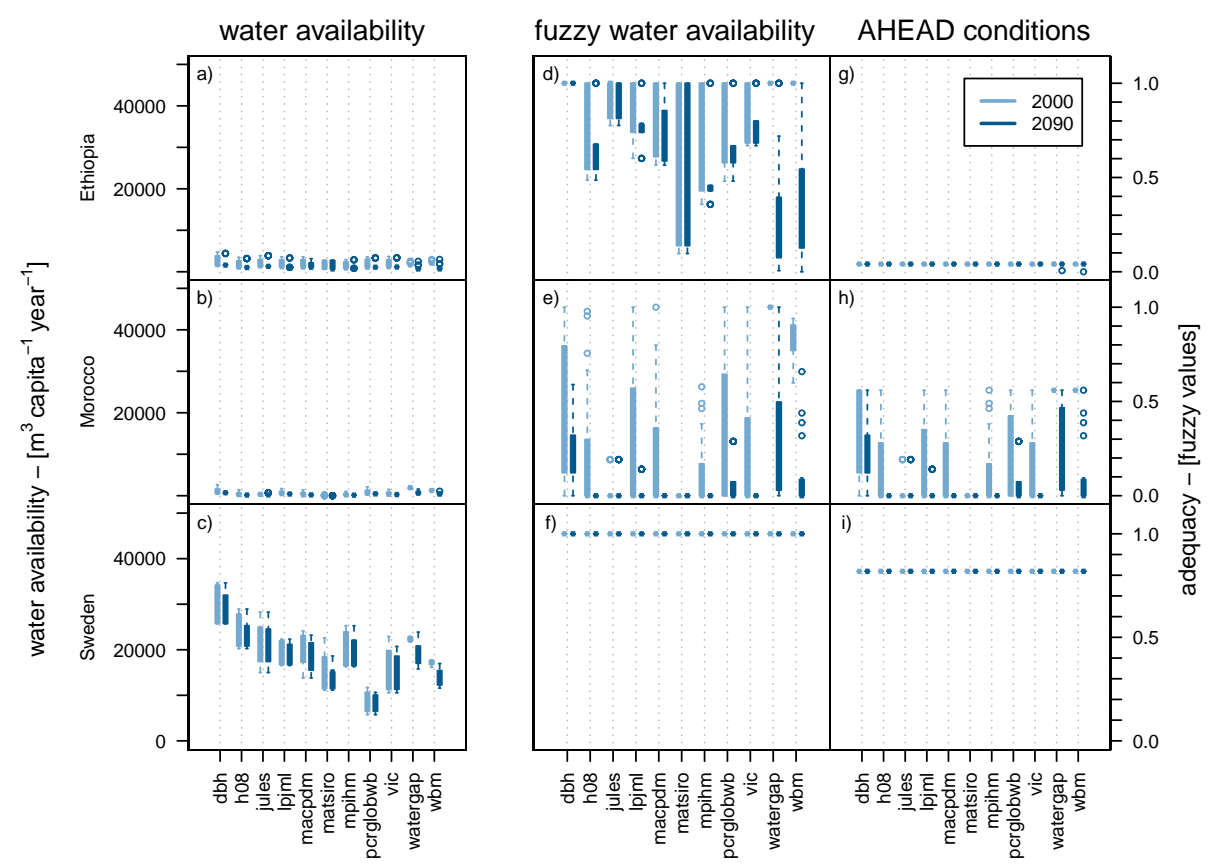

Figure 4. Examples of input data and fuzzified values/results for the examples Ethiopia, Morocco and Sweden. Left panels: per capita water availability; middle panels: fuzzified water data; and right panels: AHEAD results. Right axis labels and units (adequacy - fuzzy values) apply to middle and right panels. Results of the individual impact models are plotted from left to right within panels, showing the result range for all GCMs and RCPs for each time slice.

representing the access to satisfiers, which can differ according to prevailing possibilities and preferences. In the present implementation, the focus is on a comparable measurement of AHEAD conditions at global scale and national resolution. The selection of indicators (satisfiers) is therefore limited to data which are available at this scale, but focusses on using comprehensive satisfiers to provide a holistic perspective where possible. In the case of measuring social protection, for example, the three indicators "traditional solidarity", "institutional solidarity" and "micro-credits/micro-lending" can each contribute to a very high degree of fulfilment, reflecting different cultural preferences and development status (Cook and Kabeer, 2009).

With regard to the representation of water availability within the AHEAD framework, our approach to combine water resource availability with the access to an improved water source provides an important way forward to account for the fact that water resources alone do not guarantee access to water. Especially in developing countries, water access infrastructure poses a more important limitation to water availability, rather than the available resource (Rijsberman, 2006). At the same time, water shortages to some extent can be mitigated by good water infrastructure. In many countries of the EU, such as Germany, per capita water availability is very close to a scarcity threshold, yet few problems with water security have so far occurred as a result of good water management. Changes in both water resources and population have an effect on the per capita resource availability within a country. By selecting average per capita requirements for a life in dignity as the assessment unit, the various pressures exerted on resources can be represented by the approach. In the case of water availability, it is often the increase in population which reduces the adequacy of per capita water availability, rather than reduction in water resources.

Methodologically, the use of fuzzy logic allows for translation of inherently fuzzy concepts and data from different sources and in different units into a consistent framework. The translation of elements from a qualitative description into a quantified representation is associated with vagueness. The use of linguistic categories, as well as the representation of gradual truth values of membership to these categories, provides a means to address this vagueness in a comparable way. The aggregation of data from different sources with different units is challenging (Parsons et al., 2011), as data needs to be transformed into a compatible format in order to enable aggregation. The definition of context-specific linguistic categories allows for the range of input values to be translated into a consistent and comparable format, in the case of the present analysis a representation of the adequacy of conditions, allowing for direct comparison between countries. Other indicator-based approaches have been criticized for their normalization and aggregation methods, which do not retain important cause-and-effect relationships between elements (e.g. the well-known HDI; Kovacevic, 2011). In contrast, the AHEAD approach is not a simple aggregation 


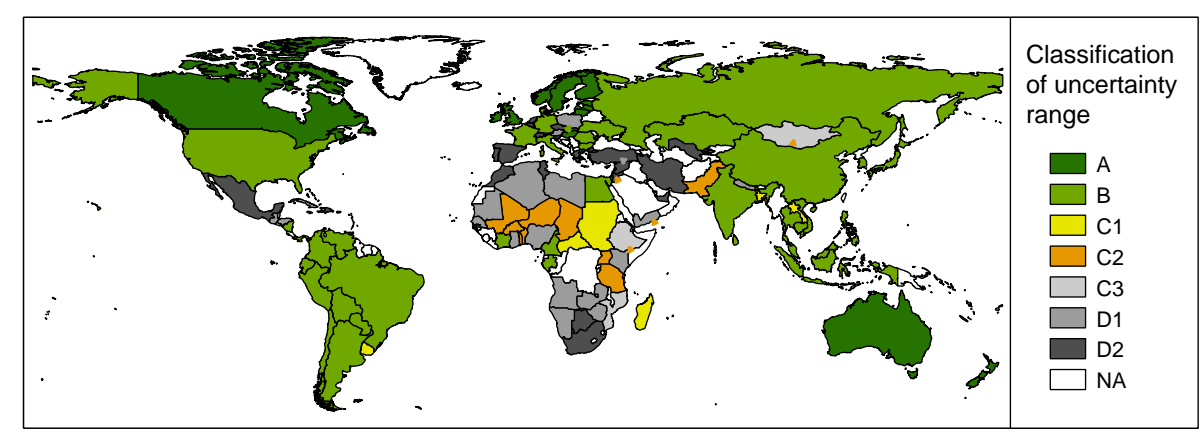

Figure 5. Classification of countries for baseline conditions following the decision tree outlined in Fig. 2. Result values for current and future calculations for all GCMs and RCPs are published on figshare (Lissner et al., 2014a).

of elements: it allows for properties of single variables to be maintained in the final result.

The approach also allows for the effects of climate change impacts on AHEAD to be assessed. As exemplified with the example of water availability, an assessment of the relevance of changes for a specific context, here the adequacy of AHEAD conditions, becomes possible. The approach can be extended in this regard, as it allows for a range of sectoral climate impacts to be assessed. Projections of climate change and impacts are subject to uncertainty, deriving from several sources. Especially in climate impact assessments, uncertainties multiply along the assessment chain (Schneider and Kuntz-Duriseti, 2002). The present approach allows for parts of such uncertainties to addressed by assessing their relevance with regard to a specific context. Of the sources of uncertainties, those deriving from the modelling set-up as well as from potential future scenarios are directly visible in modelling intercomparison efforts, such as the ISI-MIP project, as these make the range of plausible future developments visible. By analysing their relevance with regard to specific questions, the methodology presented in this paper can help in putting these result ranges into a perspective. In many cases uncertainty in future projections is high. However, as we were able to show with the example of water availability, these uncertainty ranges often do not overlap with critical thresholds for livelihood aspects - in this case water security. As results presented in Figs. 4 and 5 show, countries can be classified according to the relevance of uncertainty regarding water availability. In countries such as Sweden, modelling- and scenario-induced uncertainties are substantial, but all values are well above basic human requirements, and therefore the uncertainties do not affect water security, as the fuzzification step from column 1 to column 2 in Fig. 4 illustrates. In the examples of Ethiopia and Morocco, however, uncertainty remains relevant in this context.

The AHEAD approach also allows for changes in single components to be viewed within a wider framework of livelihood conditions. Our results show that the majority of countries with low values of AHEAD are not water-limited but otherwise restricted (Fig. 5, class B and C.1), and other development priorities are more pressing. In many countries a large inter-model spread is apparent in projections of future water availability, as visible in the example of Sweden. The translation into a fuzzy representation allows for the determination of whether this uncertainty is relevant with regard to a specific question. In Sweden, all projections are above the thresholds for water security. In countries such as Ethiopia and Morocco, the inter-model is spread is lower; however the result range is highly relevant to livelihood conditions and water security, and uncertainty remains visible in the AHEAD result. The approach can thus reveal important insights into development priorities. Modelling uncertainties have been blamed for inaction regarding climate change policies (Lorenzoni et al., 2007). Such impasses can be resolved to some extent if the visible uncertainty range is related to a specific context.

There are several limitations to the AHEAD approach and its present implementation. The use of global data at national resolution and the definition of globally applicable thresholds provides a comparable overview global AHEAD fulfilment, but is unable to include regional to local specificities. Country-specific management practices and preferences, for example, are thus not accounted for. An analysis at country scale assumes that national boundaries limit resource availability. However, especially in the food and water sectors, trade plays an important role for actual resource availability (Suweis et al., 2013; Chapagain et al., 2006). Additionally, the assessment of water requirements as an aggregate of all sectors does not take different sectoral requirements into account, with regard to quality and infrastructure, for example. More detailed analyses at finer resolutions, as, for example, proposed by Lissner et al. (2014b), can provide important further information in this regard. Finally, the implementation at country scale using annual mean water availability also assumes an even distribution of population and resources across space and time within country boundaries. Especially in large countries with uneven population distributions and diverse climatic conditions, such averages prove to be a limitation for the assessment of water availability. 
The conceptual foundation of AHEAD is based on the ideas put forward in the literature of well-being and livelihoods. Following these ideas, the identified elements of AHEAD are non-culturally specific. However, the choice of indicators to represent their fulfilment (satisfiers) can vary, for example, according to development status or culturally specific preferences. For the purpose of a global application, the availability of data sets of sufficient coverage is an important restriction. Some available data sets are limited in their ability to depict the potential range of satisfiers that could be used in order to meet the respective need. This is visible in the representation of mobility, for example. Mobility exists at different timescales, different spatial scales and with different purposes. The focus of AHEAD is on short-term and local to regional mobility, which is relevant to social networks and inclusion, for example (Urry, 2003; Cass et al., 2005), but is also relevant to the accessibility of various services (Mokhtarian et al., 2001), such as health care (Molesworth, 2006). Existing indicators with sufficient coverage to present a global picture of mobility are scarce, and the chosen indicator of motor vehicle density only represents a fraction of potential satisfiers for mobility needs. Similar restrictions apply to the other indicators used for the present calculation of AHEAD. Here, more targeted data collection with a focus on regional specificities, as well the different facets of satisfiers, would be needed.

The current application of the index exemplifies how the relevance of uncertainty deriving from modelling approaches and scenarios can be assessed, using data on potential changes in water availability. For a holistic picture, consistent scenarios for all variables would have to be used, which is outside the scope of this assessment. It is also important to note that uncertainty ranges outside the thresholds relevant to AHEAD remain important for other water-related decisions, e.g. urban water flow management. While such changes may not directly affect water security, other effects may nonetheless negatively affect the adequacy of human livelihood conditions.

Knowledge on the biophysical impacts of climate change on global scale is becoming available at increasing levels of detail (Piontek et al., 2013), while assessments of impacts on societal systems and human livelihoods and well-being remain fragmented. The AHEAD approach proposes a framework which allows for climate impacts to be systematically related to livelihoods at global to regional scales, providing a frame for the results of global modelling efforts. The adequate communication of research results is an essential requirement for the integration of scientific findings into policy decisions (Smith, 2011). The role of uncertainty in particular is often an impediment (Sigel et al., 2010). Embedding visible uncertainty of modelling output within a context allows showing where uncertainties are relevant with regard to specific questions and where they may be outside the range of relevance for the certain decisions. The results of course do not reduce the uncertainty of the modelling output, but they can help put existing uncertainties into a context. This may help in reducing the limiting and inhibiting effects that uncertainty currently has for climate change adaptation and mitigation policy decisions.

\section{Conclusions}

Uncertainty has been blamed for inaction in climate policy (Lorenzoni et al., 2007). This is also due to public misconceptions of the term uncertainty. The adequate and targeted communication of scientific results is essential in fields of high policy relevance, such as climate change research. To improve the communication and the transferability of results, adequate methodologies are urgently needed which are rooted in scientific findings but are able to bridge the gap between science and practice and able to prepare results in an applicable and understandable way. The analysis and intercomparison of available impact models, as has been done in the ISI-MIP project, is an essential step towards the active consideration of uncertainties. By integrating these results into a wider context of human well-being and livelihood requirements, the AHEAD approach provides a novel way forward in the integrated and targeted communication of applicable scientific results. 


\section{Appendix A}

Table A1. Summary of results for each variable, showing the number of countries in each class. Classes correspond to 0.2 increments $(0-<0.2$ : very low; $0.2-<0.4$ : low; $0.4-<0.6$ : intermediate; $0.6-$ $<0.8$ : high; 0.8-1: very high). The classification of the variable "water" refers to results for baseline conditions using the ensemble mean.

\begin{tabular}{lccccc}
\hline & Very low & Low & Intermediate & High & Very high \\
\hline Water & 20 & 7 & 2 & 5 & 161 \\
Food & 2 & 2 & 2 & 20 & 150 \\
Water access & 16 & 8 & 35 & 30 & 107 \\
Air & 36 & 12 & 21 & 23 & 83 \\
Health & 0 & 35 & 37 & 19 & 100 \\
Sanitation & 13 & 20 & 22 & 22 & 119 \\
Energy & 51 & 7 & 9 & 7 & 102 \\
Education & 6 & 14 & 27 & 38 & 90 \\
Mobility & 116 & 9 & 6 & 2 & 41 \\
Communication & 34 & 35 & 38 & 51 & 37 \\
Social protection & 0 & 3 & 24 & 65 & 29 \\
Economic stability & 8 & 15 & 48 & 34 & 16 \\
Political stability & 4 & 5 & 14 & 26 & 72 \\
Security & 5 & 8 & 23 & 31 & 54 \\
Social inclusion & 9 & 15 & 41 & 28 & 30 \\
Participation & 32 & 29 & 33 & 16 & 13 \\
\hline
\end{tabular}



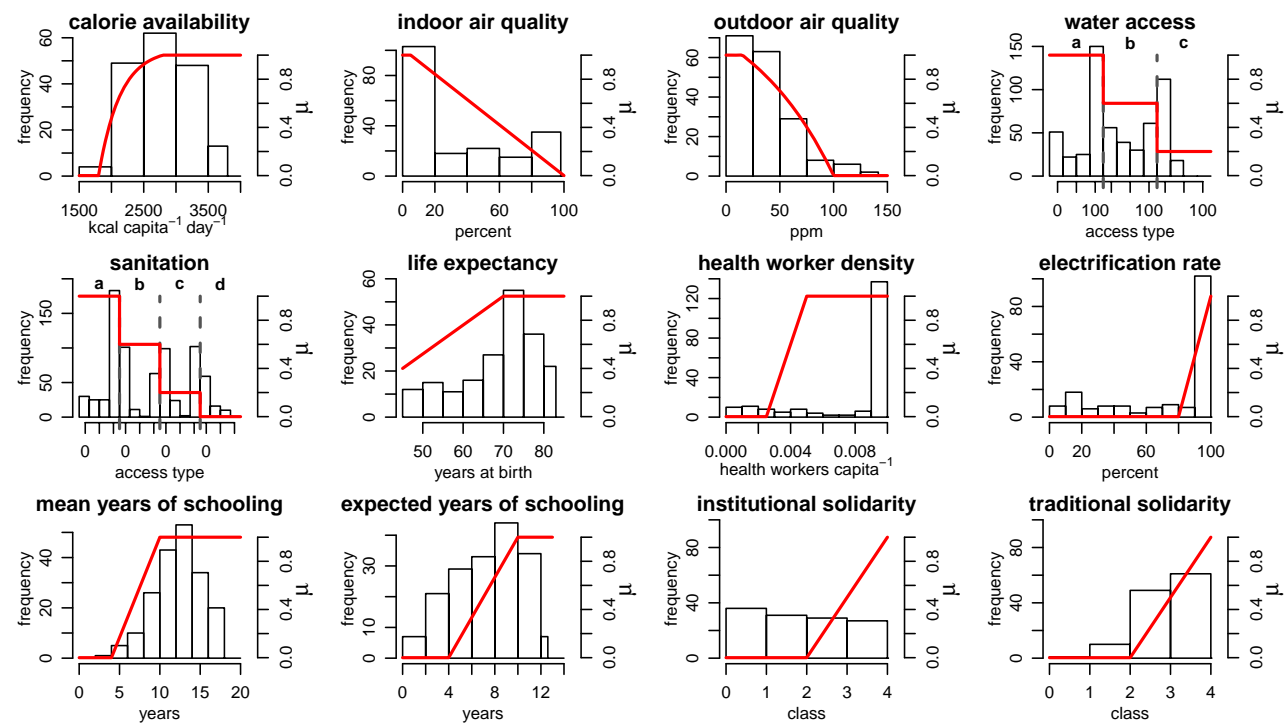

expected years of schooling
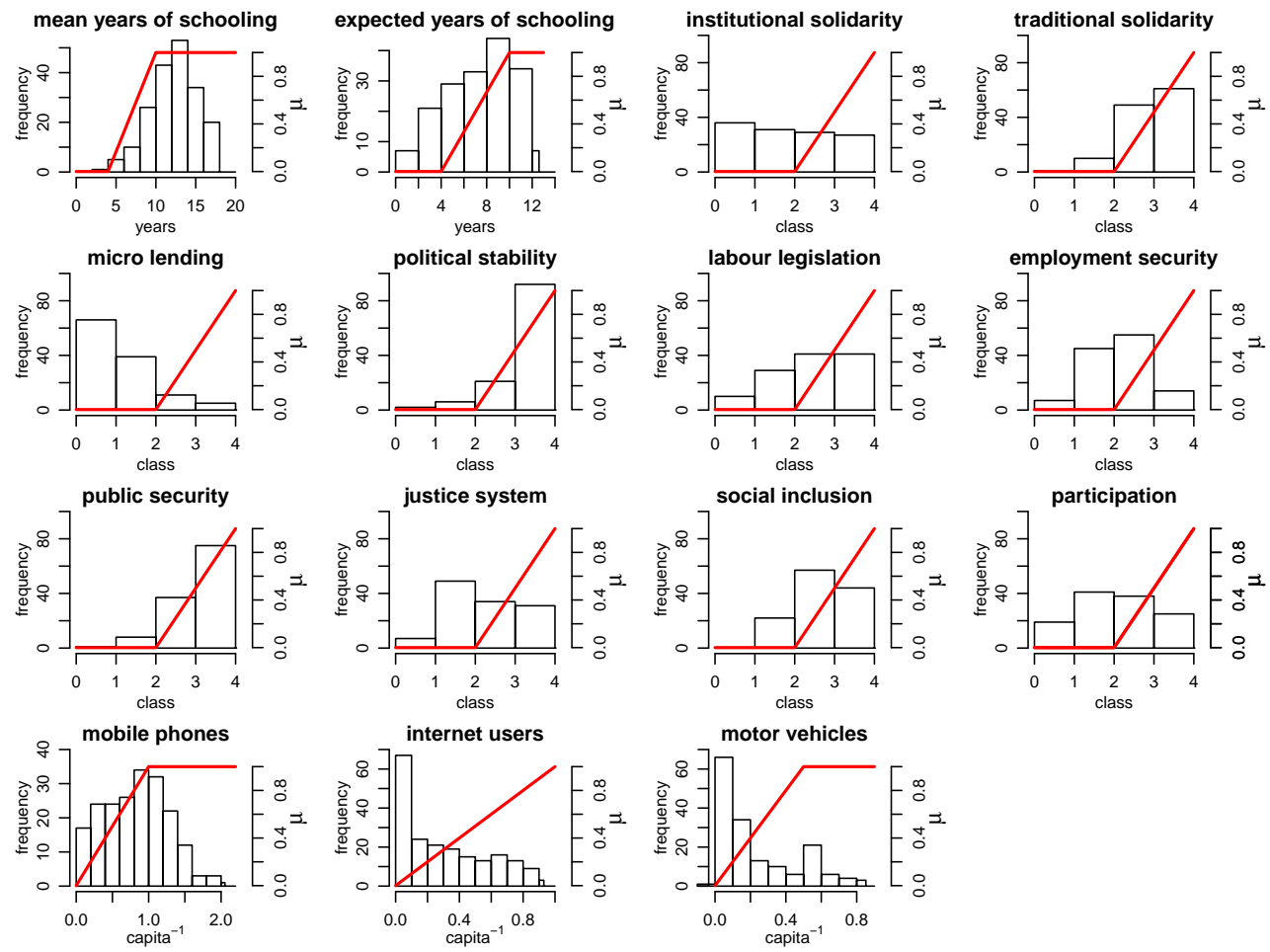

Figure A1. Frequency distributions of the original input data and the membership functions used for their fuzzification. For variable "water access": (a) piped on premises, (b) other improved access and (c) unimproved access. For variable "sanitation": (a) improved sanitation, (b) shared facilities, (c) other unimproved and (d) open defecation.

water resources 2000

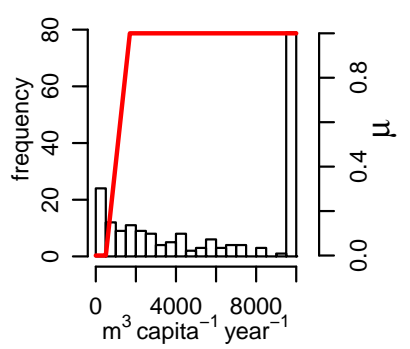

water resources 2090

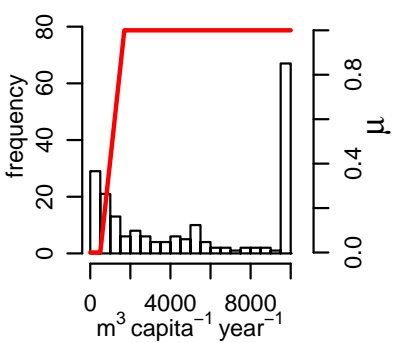

Figure A2. Frequency distributions of the input data and membership functions for water resource availability. Values show the ensemble mean across all ISI-MIP climate and impact models for the two 30 -year periods. 
Acknowledgements. The work was developed within a project funded by the German Federal Ministry of the Environment, Nature Conservation and Nuclear Safety, specifically through the International Climate Initiative (Internationale Klimaschutzinitiative, IKI) and PROGRESS: Spitzenforschung und Innovation in den Neuen Ländern (PROGRESS: Potsdam Research Cluster for Georisk Analysis, Environmental Change and Sustainability) (grant no. 03IS2191B). For their roles in producing, coordinating, and making the ISI-MIP model output available, we acknowledge the modelling groups (as listed/cited in the text) and the ISI-MIP coordination team. We also wish to thank the two anonymous reviewers for suggestions which helped in improving the manuscript.

Edited by: R. Pavlick

\section{References}

Alkire, S.: Dimensions of Human Development, World Development, 30, 181-205, doi:10.1016/S0305-750X(01)00109-7, 2002.

Anand, P., Santos, C., and Smith, R.: The measurement of capabilities, in: Arguments for a Better World: Essays in Honor of Amartya Sen - Volume I: Ethics, Welfare and Measurement, edited by: Basu, K. and Kanbur, R., Oxford University Press, Oxford, New York, 285-310, 2008.

Appelgren, B. G.: Appendix 3: Keynote Paper - Management of Water Scarcity: National water policy reform in realtion to regional development cooperation, in: Proceedings of the Second Expert Consultation on National Water Policy Reform in the Near East, FAO, Cairo, Egypt, 1-14, 1998.

Best, M. J., Pryor, M., Clark, D. B., Rooney, G. G., Essery, R. L. H., Ménard, C. B., Edwards, J. M., Hendry, M. A., Porson, A., Gedney, N., Mercado, L. M., Sitch, S., Blyth, E., Boucher, O., Cox, P. M., Grimmond, C. S. B., and Harding, R. J.: The Joint UK Land Environment Simulator (JULES), model description Part 1: Energy and water fluxes, Geosci. Model Dev., 4, 677-699, doi:10.5194/gmd-4-677-2011, 2011.

Bhuwanee, T., Opertti, R., Lili, J., and Jahn, K.: The Basic Education in Africa Programme (BEAP), Tech. rep., BREDA/IBEUNESCO/GTZ, Eschborn, 2009.

Bondeau, A., Smith, P. C., Zaehle, S., Schaphoff, S., Lucht, W., Cramer, W., Gerten, D., Lotze-Campen, H., Müller, C., Reichstein, M., and Smith, B.: Modelling the role of agriculture for the 20th century global terrestrial carbon balance, Global Change Biol., 13, 679-706, doi:10.1111/j.13652486.2006.01305.x, 2007.

Brown, A. and Matlock, M. D.: A Review of Water Scarcity Indices and Methodologies, Tech. rep., University of Arkansas, The Sustainability Consortium, Tempe, Arizona USA, 2011.

Cass, N., Shove, E., and Urry, J.: Social exclusion, mobility and access, Sociolog. Rev., 53, 539-555, doi:10.1111/j.1467954X.2005.00565.x, 2005.

Chambers, R. and Conway, G. R.: Sustainable rural livelihoods: practical concepts for the 21st century, IDS Discussion Paper, IDS Discussion Paper 296, Institute of Development Studies, Brighton, UK, 1991.

Chapagain, A. K., Hoekstra, A. Y., and Savenije, H. H. G.: Water saving through international trade of agricultural products, Hydrol. Earth Syst. Sci., 10, 455-468, doi:10.5194/hess-10-4552006, 2006.
Chen, L., Evans, T., Anand, S., Boufford, J. I., Brown, H., Chowdhury, M., Cueto, M., Dare, L., Dussault, G., Elzinga, G., Fee, E., Habte, D., Hanvoravongchai, P., Jacobs, M., Kurowski, C., Michael, S., Pablos-Mendez, A., Sewankambo, N., Solimano, G., Stilwell, B., de Waal, A., and Wibulpolprasert, S.: Human resources for health: overcoming the crisis, Lancet, 364, 19841990, doi:10.1016/S0140-6736(04)17482-5, 2004.

Cook, S. and Kabeer, N.: Socio-economic security over the life course: A global agenda review of social protection, Institute of Development Studies at the University of Sussex - Centre for Social Protection, Sussex, UK, 2009.

Costanza, R., Fisher, B., Ali, S., Beer, C., Bond, L., Boumans, R., Danigelis, N., Dickinson, J., Elliott, C., and Farley, J.: Quality of life: An approach integrating opportunities, human needs, and subjective well-being, Ecol. Econ., 61, 267-276, doi:10.1016/j.ecolecon.2006.02.023, 2007.

Cruz, I., Stahel, A., and Max-Neef, M.: Towards a systemic development approach: Building on the HumanScale Development paradigm, Ecol. Econ., 68, 2021-2030, doi:10.1016/j.ecolecon.2009.02.004, 2009.

Cummins, R. A.: The domains of life satisfaction: An attempt to order chaos, Social Indicat. Res., 38, 303-328, doi:10.1007/BF00292050, 1996.

de Crombrugghe, D., Farla, K., Meisel, N., de Neubourg, C., Aoudia, J. O., and Szirmai, A.: Institutional Profiles Database III: Presentation of the Institutional Profiles Database 2009 (IDP 2009), Tech. rep., DGTPE, Paris, France, 2009.

Desai, M. A., Mehta, S., and Smith, K. R.: Indoor smoke from solid fuels Assessing the environmental burden of disease at national and local levels, in: Environmenzal Burden of Disease Series, No. 4, edited by: Prüss-Üstün, A., Campbell-Lendrum, D., Corvalán, C., and Woodward, A., World Health Organization, Geneva, 2004.

Dessai, S. and Hulme, M.: Does climate adaptation policy need probabilities?, Climate Policy, 4, 107-128, doi:10.3763/cpol.2004.0411, 2004.

Diener, E., Suh, E., Lucas, R., and Smith, H.: Subjective well-being: three decades of progress, Psycholog. Bull., 125, 276-302, 1999.

Dietz, T., Rosa, E., and York, R.: Environmentally efficient wellbeing: Rethinking sustainability as the relationship between human well-being and environmental impacts, Human Ecol. Rev., 16, 114-123, 2009.

Döll, P., Kaspar, F., and Lehner, B.: A global hydrological model for deriving water availability indicators: model tuning and validation, J. Hydrol., 270, 105-134, doi:10.1016/S00221694(02)00283-4, 2003.

Doyal, L. and Gough, I.: A theory of human needs, Crit. Social Policy, 4, 6-38, doi:10.1177/026101838400401002, 1984.

Falkenmark, M.: Meeting water requirements of an expanding world population, Philos. T. Roy. Soc. Lond. B, 352, 929-936, 1997.

Falkenmark, M. and Rockström, J.: Balancing water for humans and nature. The new approach in ecohydrology, Earthscan, London, UK, 2004.

FAO: Human energy requirements, Tech. rep., FAO/WHO/UNU, Rome, 2001.

FAOSTAT: FAOSTAT database, Food and Agriculture Organization of the United Nations (FAO), http://faostat.fao.org/site/354/ default.aspx (last access: October 2013), 2009. 
Gasper, D.: Securing Humanity: Situating "Human Security" as Concept and Discourse, J. Human Develop., 6, 221-245, doi:10.1080/14649880500120558, 2005.

Gasper, D.: What is the capability approach? Its core, rationale, partners and dangers, J. Socio-Econ., 36, 335-359, doi:10.1016/j.socec.2006.12.001, 2007.

Gaye, A.: Access to Energy and Human Development, Human Development Report 2007/2008, Occasional Paper, UNDP, 2008.

Gerten, D., Heinke, J., Hoff, H., Biemans, H., Fader, M., and Waha, K.: Global water availability and requirements for future food production, J. Hydrometeorol., 12, 885-899, doi:10.1175/2011JHM1328.1, 2011.

Gosling, S. N. and Arnell, N. W.: Simulating current global river runoff with a global hydrological model: model revisions, validation, and sensitivity analysis, Hydrol. Process., 25, 1129-1145, doi:10.1002/hyp.7727, 2011.

Grey, D., Garrick, D., Blackmore, D., Kelman, J., Muller, M., and Sadoff, C.: Water security in one blue planet: twenty-first century policy challenges for science, Philos. T. Roy. Soc. A, 371, 20120406, doi:10.1098/rsta.2012.0406, 2013.

Hanasaki, N., Kanae, S., Oki, T., Masuda, K., Motoya, K., Shirakawa, N., Shen, Y., and Tanaka, K.: An integrated model for the assessment of global water resources - Part 1: Model description and input meteorological forcing, Hydrol. Earth Syst. Sci., 12, 1007-1025, doi:10.5194/hess-12-1007-2008, 2008.

Hare, W. L., Cramer, W., Schaeffer, M., Battaglini, A., and Jaeger, C. C.: Climate hotspots: key vulnerable regions, climate change and limits to warming, Reg. Environ. Change, 11, 1-13, doi:10.1007/s10113-010-0195-4, 2011.

Hempel, S., Frieler, K., Warszawski, L., Schewe, J., and Piontek, F.: A trend-preserving bias correction - the ISI-MIP approach, Earth Syst. Dynam., 4, 219-236, doi:10.5194/esd-4-219-2013, 2013.

Howard, G. and Bartram, J.: Domestic Water Quantity, Service Level and Health, World Health Organization, Geneva, 2003.

IDP: Institutional Profiles Database 2009 (Data), http://www.cepii. fr/institutions/EN/ipd.asp (last access: October 2013), 2009.

King, G. and Murray, C.: Rethinking human security, Polit. Sci. Quarter., 116, 585-610, 2001.

Klugman, J.: Sustainability and Equity: A Better Future for All, Human Development Report, Human Development Report, UNDP, New York, USA, 2011.

Klugman, J., Rodríguez, F., and Choi, H.-J.: The HDI 2010: new controversies, old critiques, J. Econ. Inequal., 9, 249-288, doi:10.1007/s10888-011-9178-z, 2011.

Kovacevic, M.: Review of HDI Critiques and Potential Improvements, Human Development Research Paper, Human Development Research Paper 2010/33, UNDP, 2011.

Kropp, J., Lüdeke, M. K. B., and Reusswig, F.: Global Analysis and Distribution of Unbalanced Urbanization Processes: The FAVELA Syndrome, GAIA, 10, 109-120, 2001.

Kropp, J. P., Block, A., Reusswig, F., and Zickfeld, K.: Semiquantitative Assessment of Regional Climate Vulnerability: the North-Rhine Westphalia Study, Climatic Change, 76, 265-290, doi:10.1007/s10584-005-9037-7, 2006.

Liang, X., Lettenmaier, D. P., Wood, E. F., and Burges, S. J.: A simple hydrologically based model of land surface water and energy fluxes for general circulation models, J. Geophys. Res., 99, 14415, doi:10.1029/94JD00483, 1994.
Lillemo, S. C. and Halvorsen, B.: The impact of lifestyle and attitudes on residential firewood demand in Norway, Biomass Bioenergy, 57, 13-21, doi:10.1016/j.biombioe.2013.01.024, 2013.

Lissner, T. K., Reusser, D. E., Lakes, T., and Kropp, J. P.: A systematic approach to assess human well-being demonstrated for impacts of climate change, Change Adapt. Socio-Ecol. Syst., doi:10.2478/cass-2014-0010, in press, 2014.

Lissner, T. K., Holsten, A., Walther, C., and Kropp, J. P.: Towards sectoral and standardised vulnerability assessments: the example of heatwave impacts on human health, Climatic Change, 112, 687-708, doi:10.1007/s10584-011-0231-5, 2012.

Lissner, T. K., Reusser, D. E., Schewe, J., Lakes, T., and Kropp, J. P.: Supplementary material: Climate impacts on human livelihoods: where uncertainty matters in projections of water availability, Figshare, doi:10.6084/m9.figshare.1114937, 2014a.

Lissner, T. K., Sullivan, C. A., Reusser, D. E., and Kropp, J. P.: Determining regional limits and sectoral constraints for water use, Hydrol. Earth Syst. Sci., 18, 4039-4052, doi:10.5194/hess-184039-2014, 2014b.

Littig, B. and Griessler, E.: Social sustainability: a catchword between political pragmatism and social theory, Int. J. Sustain. Develop., 8, 65-79, 2005.

Lorenzoni, I., Nicholson-Cole, S., and Whitmarsh, L.: Barriers perceived to engaging with climate change among the UK public and their policy implications, Global Environ. Change, 17, 445459, doi:10.1016/j.gloenvcha.2007.01.004, 2007.

Maslow, A.: A theory of human motivation, Psycholog. Rev., 50, 370-396, 1943.

Max-Neef, M.: Development and human needs, in: Real-Life Economics: Understanding Wealth Creation, edited by: Ekins, P. and Max-Neef, M., Routledge, London, 197-213, 1992.

Mayer, A., Mechler, B., Schlindwein, A., and Wolke, R.: Fuzzy Logic, Addison-Wesley, Bonn, 1993.

McHale, J. and McHale, M. C.: Meeting Basic Human Needs, Ann. Am. Acad. Polit. Social Sci., 442, 13-27, doi:10.1177/000271627944200103, 1979.

MEA: Ecosystems and human well-being: Synthesis, Millennium Ecosystem Assessment, Island Press, Washington, D.C., 2005.

Mokhtarian, P. L., Salomon, I., and Redmond, L. S.: Understanding the Demand for Travel: It's Not Purely "Derived", Innovation, Eur. J. Social Sci. Res., 14, 355-380, 2001.

Molesworth, K.: Mobility and Health: The impact of transport provision on direct and proximate determinants of access to health services, International Forum for Rural Transport and Development, London, UK, 2006.

Moss, R. H., Edmonds, J. A., Hibbard, K. A., Manning, M. R., Rose, S. K., van Vuuren, D. P., Carter, T. R., Emori, S., Kainuma, M., Kram, T., Meehl, G. A., Mitchell, J. F. B., Nakicenovic, N., Riahi, K., Smith, S. J., Stouffer, R. J., Thomson, A. M., Weyant, J. P., and Wilbanks, T. J.: The next generation of scenarios for climate change research and assessment, Nature, 463, 747-56, doi:10.1038/nature08823, 2010.

Narayan, D., Chambers, R., Shah, M. K., and Petesch, P.: Voices of the Poor. Crying Out for Change, Oxford University Press for the World Bank, New York, 2000. 
Nussbaum, M. C.: Women and Human Development: The Capabilities Approach, Cambridge University Press, Cambridge, 2000.

O’Brien, K. L., Leichenko, R., Kelkar, U., Venema, H., Aandahl, G., Tompkins, H., Javed, A., Bhadwal, S., Barg, S., and Nygaard, L.: Mapping vulnerability to multiple stressors: climate change and globalization in India, Global Environ. Change, 14, 303-313, doi:10.1016/j.gloenvcha.2004.01.001, 2004.

OECD/IEA: World Energy Outlook 2009, International Energy Agency - IEA, Paris, 2009.

O’Neill, B., Carter, T. R., Ebi, K. L., Edmonds, J., Hallegatte, S., Kemp-Benedict, E., Kriegler, E., Mearns, L., Moss, R., Riahi, K., Ruijven, B. V., and van Vuuren, D.: Meeting Report of the Workshop on The Nature and Use of New Socioeconomic Pathways for Climate Change Research, 2-4 November 2011, Boulder, CO, 2012.

O'Riordan, T.: Sustainability for wellbeing, Environ. Innov. Soc. Trans., 6, 24-34, doi:10.1016/j.eist.2012.12.001, 2013.

Parsons, M. A., Godoy, O., LeDrew, E., de Bruin, T. F., Danis, B., Tomlinson, S., and Carlson, D.: A conceptual framework for managing very diverse data for complex, interdisciplinary science, J. Inform. Sci., 37, 555-569, doi:10.1177/0165551511412705, 2011.

Piontek, F., Müller, C., Pugh, T. A. M., Clark, D. B., Deryng, D., Elliott, J., Colón González, F. D. J., Flörke, M., Folberth, C., Franssen, W., Frieler, K., Friend, A. D., Gosling, S. N., Hemming, D., Khabarov, N., Kim, H., Lomas, M. R., Masaki, Y., Mengel, M., Morse, A., Neumann, K., Nishina, K., Ostberg, S., Pavlick, R., Ruane, A. C., Schewe, J., Schmid, E., Stacke, T., Tang, Q., Tessler, Z. D., Tompkins, A. M., Warszawski, L., Wisser, D., and Schellnhuber, H. J.: Multisectoral climate impact hotspots in a warming world, P. Natl. Acad. Sci. USA, 111, 3233-3238, doi:10.1073/pnas.1222471110, 2013.

Pope III, C., Burnett, R., Thun, M., Calle, E., Krewski, D., Ito, K., and Thurston, G.: Lung cancer, cardiopulmonary mortality, and long-term exposure to fine particulate air pollution, Jama, 287, 1132-1141, 2002.

Rijsberman, F. R.: Water scarcity: Fact or fiction?, Agr. Water Manage., 80, 5-22, doi:10.1016/j.agwat.2005.07.001, 2006.

Schewe, J., Heinke, J., Gerten, D., Haddeland, I., Arnell, N. W., Clark, D. B., Dankers, R., Eisner, S., Fekete, B. M., ColónGonzález, F. J., Gosling, S. N., Kim, H., Liu, X., Masaki, Y., Portmann, F. T., Satoh, Y., Stacke, T., Tang, Q., Wada, Y., Wisser, D., Albrecht, T., Frieler, K., Piontek, F., Warszawski, L., and Kabat, P.: Multimodel assessment of water scarcity under climate change, P. Natl. Acad. Sci. USA, 111, 3245-3250, doi:10.1073/pnas.1222460110, 2014.

Schneider, S. H. and Kuntz-Duriseti, K.: Uncertainty and climate change policy, in: Climate Change Policy: A Survey, edited by: Schneider, S. H., Rosencranz, A., and Niles, J. O., chap. 2, Island Press, Washington, D.C., 2002.

Schneider, S. H., Semenov, S., Patwardhan, A., Burton, I., Magadza, C., Oppenheimer, M., Pittock, A. B., Rahman, A., Smith, J. B., Suarez, A., and Yamin, F.: Assessing key vulnerabilities and the risk from climate change, in: Climate Change 2007: Impacts, Adaptation and Vulnerability. Contribution ofWorking Group II to the Fourth Assessment Report of the Intergovernmental Panel on Climate Change, edited by: Parry, M., Canziani, O., Palutikof, J., van der Linden, P., and Hanson, C., chap. 19, Cambridge University Press, Cambridge, UK, 779-810, 2007.
Scoones, I.: Sustainable Rural Livelihoods: A Framework for Analysis, IDS Working Paper, IDS Working Paper 72, Institute of Development Studies, Brighton, UK, 1998.

Sen, A.: Commodities and Capabilities, Oxford University Press, 1985.

Sen, A.: Capability and well-being, in: The Quality of Life, edited by: Nussbaum, M. and Sen, A., vol. 453 of The quality of life, Clarendon Press, 30-53, 1993.

Sigel, K., Klauer, B., and Pahl-Wostl, C.: Conceptualising uncertainty in environmental decision-making: The example of the EU water framework directive, Ecol. Econ., 69, 502-510, doi:10.1016/j.ecolecon.2009.11.012, 2010.

Smith, K.: We are seven billion, Nat. Clim. Change, 1, 331-335, 2011.

Smith, L. A. and Stern, N.: Uncertainty in science and its role in climate policy, Philos. T. Roy. Soc. A, 369, 4818-41, doi:10.1098/rsta.2011.0149, 2011.

Stiglitz, J., Sen, A., and Fitoussi, J.: Report by the Commission on the Measurement of Economic Performance and Social Progress, Commission on the Measurement of Economic Performance and Social Progress, Paris, 2009.

Stacke, T. and Hagemann, S.: Development and evaluation of a global dynamical wetlands extent scheme, Hydrol. Earth Syst. Sci., 16, 2915-2933, doi:10.5194/hess-16-2915-2012, 2012.

Suweis, S., Rinaldo, A., Maritan, A., and D'Odorico, P.: Watercontrolled wealth of nations., Proceedings of the National Academy of Sciences of the United States of America, 110, 4230-3, doi:10.1073/pnas.1222452110, 2013.

Takata, K., Emori, S., and Watanabe, T.: Development of the minimal advanced treatments of surface interaction and runoff, Global Planetary Change, 38, 209-222, doi:10.1016/S09218181(03)00030-4, 2003.

Tang, Q., Oki, T., Kanae, S., and Hu, H.: The Influence of Precipitation Variability and Partial Irrigation within Grid Cells on a Hydrological Simulation, J. Hydrometeorol., 8, 499-512, doi:10.1175/JHM589.1, 2007.

Taylor, K. E., Stouffer, R. J., and Meehl, G. A.: An Overview of CMIP5 and the Experiment Design, B. Am. Meteorol. Soc., 93, 485-498, doi:10.1175/BAMS-D-11-00094.1, 2012.

UN: The Universal Declaration of Human Rights, 1948.

UNDP: New dimensions of human security, Human Development Report, Chapter 2, New York, USA, 22-46, 1994.

UNDP: International Human Development Indicators, http:// hdrstats.undp.org/en/indicators/default.html (last access: October 2013), 2009.

UN ICT Task Force: Measuring ICT: The global status of ICT indicators, Partnership on measuring ICT for development, New York, NY, USA, 2005.

Urry, J.: Social networks, travel and talk, British J. Sociol., 54, 155175, doi:10.1080/0007131032000080186, 2003.

Wada, Y., van Beek, L. P. H., van Kempen, C. M., Reckman, J. W. T. M., Vasak, S., and Bierkens, M. F. P.: Global depletion of groundwater resources, Geophys. Res. Lett., 37, L20402, doi:10.1029/2010GL044571, 2010.

Warszawski, L., Frieler, K., Huber, V., Piontek, F., Serdeczny, O., and Schewe, J.: The Inter-Sectoral Impact Model Intercomparison Project (ISI-MIP): project framework, P. Natl. Acad. Sci. USA, 111, 3228-3232, doi:10.1073/pnas.1312330110, 2014. 
Weigel, V.: The basic needs approach: Overcoming the poverty of homo oeconomicus, World Development, 14, 1423-1434, doi:10.1016/0305-750X(86)90041-0, 1986.

Whitlock, G., Lewington, S., Sherliker, P., Clarke, R., Emberson, J., Halsey, J., Qizilbash, N., Collins, R., and Peto, R.: Body-mass index and cause-specific mortality in 900000 adults: collaborative analyses of 57 prospective studies, Lancet, 373, 1083-1096, doi:10.1016/S0140-6736(09)60318-4, 2009.

WHO: Global Health Observatory Data Repository, http://apps. who.int/gho/data/ (last access: October 2013), 2009.
Wicks, E.: The Meaning of "Life": Dignity and the Right to Life in International Human Rights Treaties, Human Rights Law Rev., 12, 199-219, doi:10.1093/hrlr/ngs002, 2012.

Wisser, D., Fekete, B. M., Vörösmarty, C. J., and Schumann, A. H.: Reconstructing 20th century global hydrography: a contribution to the Global Terrestrial Network-Hydrology (GTN-H), Hydrol Earth Syst. Sci., 14, 1-24, doi:10.5194/hess-14-1-2010, 2010.

World Bank: World Bank Open Data, http://data.worldbank.org/ indicator (last access: October 2013), 2009.

Zadeh, L.: Fuzzy Sets, Inform. Control, 8, 338-353, 1965. 